\title{
Major Influences on Business Purchases
}

\author{
Chief Assist. Prof. PhD Tsanko Stefanov \\ St. Cyril and St. Methodius University of Veliko Turnovo, Veliko Turnovo, Bulgaria \\ cankostefanov@abv.bg
}

\begin{abstract}
Various participants are involved in the purchase of the goods and services for the business. A common practice when purchasing important goods is the creation of purchasing committees composed of technical experts and senior executives. In addition, B-to-B marketing professionals are now facing a new generation of supply managers who are more qualified. Therefore, companies need to have well-trained marketing professionals able to work with these well-prepared buyers. The purpose of the article is to present a model of business buyer behavior and to find out how marketing and other incentives affect the purchasing organization and cause certain reactions from the buyer.
\end{abstract}

Keywords: B-to-B marketing professionals, business purchases

JEL Code: M30, M31; doi:10.36997/IJUSV-ESS/2019.8.1.104

\section{Въведение}

При пазаруването на необходимите за бизнеса стоки и услуги са включени различни участници. Често срещана практика при закупуването на важни стоки е създаването на комисии по покупките, съставени от технически експерти и високопоставени ръководители.

Освен това, B-to-B маркетинг специалистите сега са изправени пред ново поколение мениджъри по доставките, които са по-квалифицирани. Ето защо, компаниите трябва да имат добре обучени маркетинг специалисти и търговци, които да могат да работят с тези добре подготвени купувачи. Целта на разработката е да се представи модел на поведение на бизнес-купувач и да се потьрси отговор как маркетингът и други стимули влияят на купуващата организация и предизвикват определени реакции от страна на купувача.

\section{1. Основни влияния върху бизнес покупките}

За да насочат в правилна посока усилията си, специалистите по маркетинг в бизнеса трябва да изяснят: Кои са главните участници в процеса на вземането на решения? Върху кои решения влияят те? Каква е степента на влиянието им? Какви критерии за оценка използват? Когато в Центъра за покупки участват много хора, специалистът по маркетинг няма да има времето или ресурсите да достигне до всички. По-малките продавачи се съсредоточават върху ключовите влияещи фигури. А по-големите продавачи се ориентират към дълбочинно продаване на много равнища, за да достигнат до колкото е възможно повече членове на Центъра за покупки. Техните търговци буквално „живеят” с най-големите си клиенти. В общи линии, най-преуспелите компании разчитат предимно на връзките, за да разкрият скритите влияния върху покупките и по този начин да „спечелят” даден клиент. Центърьт за покупки може да бъде много динамичен, затова специалистите по маркетинг трябва периодично да преразглеждат предложенията си, както и към кои участници в центъра те да са насочени.

За да разработи добри маркетингови стратегии, специалистът по маркетинг трябва да разбере какво се случва вътре в организацията. Само така стимулите ще са в състояние да предизвикат реакции, изразяващи се в покупки. Продуктът трябва да отговаря на изискванията на купувача по отношение цена и качество, да бъде доставен на точното място и в определен срок. „Инвеститорите лесно могат да движат капиталите си по стоковия пазар, но една компания се нуждае от по-дългосрочна перспектива, на чиято база да взима решения 
да се развива - дали да се разраства, да инвестира или не” (Kotler, 2000, p. 93). Затова се отчитат и компонентите на макрообкръжението, а именно демографски, икономически, политически, технологически, културни и др.

Вътре в организацията купувач дейността по покупката се състои от две главни части: „a) център, извършващ покупката, който обхваща всички хора, участващи във вземането на решение за покупка, б) самият процес на вземане на решение за покупка. Модельт показва, че центърьт, извършващ покупката, и процесът на вземане на решение за покупка се влияят от вътрешните организационни, междуличностните и индивидуалните фактори, както и от фактори на външната среда. Центърьт за вземане на решения разглежда интерперсонално детерминанти на поведението, а именно дейностите, взаимодействията между членовете на екипа и отношенията между тях“ (Webster \&Wind, 1972, p. 12).

Най-голямо влияние при прякото и при модифицираното прекупуване имат търговските агенти, докато при новите покупки по-влиятелни са хора от други отдели на компанията. Инженерният персонал влияе в най-голяма степен при избора на компонентите на продукта, а тьрговските агенти - при избора на доставчиците. Това са само част от хората, участващи в групата (центьра) за пазаруване.

\section{2. Центьр за покупки}

Уебстьр и Уинд наричат звеното, което взема решение в една пазаруваща организация Център за покупки, като той е съставен от всички индивиди и групи, участващи в процеса на вземане на решение за покупки, и които споделят някои общи цели и рискове, които произтичат от решението. Центърът за покупки включва членове на организацията, изпълняващи някоя от следните роли в процеса на вземането на решение:

- Инициатори - хората, които настояват нещо да бъде купено, включително ползватели или други;

- Ползватели - онези, които ще използват продукта или услугата. Често ползвателите инициират предложението за покупка и помагат да се определят изискванията към продукта;

- Влияещи - хора, които влияят върху решението за покупка, включително техническият персонал. Често те помагат да се определят спецификациите, а освен това осигуряват информация за оценка на алтернативите;

- Решаващи - онези, които решават какви да бъдат изискванията към продукта или към доставчиците;

- Одобряващи - хората, които одобряват предложените действия от страна на решаващите или купуващите;

- Купуващи - хора, които са официално упълномощени да изберат доставчика и да уговорят условията на продажба, вкл. и висши мениджъри. Купуващите могат да помогнат да се оформят спецификациите на продукта, но главната им роля е да изберат тьрговците и да преговарят с тях;

- Стражи - хора, които притежават властта да препятстват достьпа на продавачи или на информация до членове на Центъра за покупки. Това са търговски агенти, секретари, телефонисти.

Бизнес купувачите, в сравнение с тези на потребителски стоки, обикновено са изправени пред много по-сложни решения за покупка. Същата обикновено включва големи парични суми, сложни технически и икономически съображения и взаимодействия между много хора на различни равнища в организацията на купувача. Тъй като покупката е посложна, бизнес купувачите може да се нуждаят от повече време, за да вземат решение. Освен 
това, процесьт на бизнес покупката обикновено е по-формализиран от този на потребителската покупка. Големите бизнес покупки обикновено изискват подробни спецификации на продуктите, писмени поръчки за покупка, внимателно търсене на доставчици и официално одобрение.

И не на последно място, в процеса на бизнес покупка купувачът и продавачът често са много по-зависими един от друг. Специалистите по B-to-B маркетинг може да работят в тясно сътрудничество с клиентите си през всички етапи от процеса на покупка - като се започне от оказване на помощ за разпознаване на проблемите, през намиране на решения, и се стигне до помощни дейности след покупката. На практика продавачите често приспособяват предложенията си според индивидуалните потребности на клиентите. В краткосрочен план продажбите може да се предоставят на доставчици, които удовлетворяват непосредствените потребности на купувачите от стоки и услуги. В дългосрочен план обаче, специалистите по B-to-B маркетинг извършват продажбите на клиента и създават допълнителна стойност за него, като отговарят на текущите нужди и му партнират, помагайки му да решава проблемите си. „Уебстьр и Уинд предлагат индивидуалните участници в процеса да бъдат анализирани според техните: мотивация; когнитивна структура; персоналност; способност да се учат (т.е. да придобиват опит) и от гледна точка на начина, по който възприемат своите роли в центъра за покупка“ (Stanimirov, 2007, p. 46).

Много компании-клиенти сега практикуват т.нар. „разработване на доставчици”, като систематично изграждат мрежи от доставчици-партньори, осигуряващи им подходяща и надеждна доставка на продукти и материали, които те използват или за производство на собствени продукти, или да ги препродават на други. „Закупуването на стоки и суровини от гледна точка на организацията и технологията на доставките се заключава във физическото движение на продуктите. Следователно вниманието се концентрира върху стоковите борси и сделките извършвани там“ (Perkov \&Koralev, 2012, р.90). Бизнес купувачите са подвластни на много влияния при вземането на решенията си. Когато офертите на доставчиците се различават значително, купувачите са по-отговорни в избора си и обръщат повече внимание на икономическите фактори.

Най-общо, бизнес купувачите са подвластни на следните основни влияния: на средата, на организацията, междуличностни, индивидуални и културни фактори.

Фактори на средата. В макросредата бизнес купувачите обръщат голямо внимание на многобройните икономически фактори, вкл. лихвените проценти и равнищата на производство, инвестициите и равнището на потребление. При рецесия бизнес купувачите намаляват инвестициите си в заводи, оборудване и запаси. Специалистите по маркетинг могат да направят малко, за да стимулират общото търсене в периоди на рецесия; те могат само да се борят по-ожесточено да увеличат или да запазят дела си в съществуващото търсене. Положителното в случая е, че компаниите, които се боят от недостиг на материали, често купуват и поддържат големи запаси, като обикновено подписват дългосрочни договори с доставчиците, за да си осигурят устойчиво снабдяване.

Бизнес купувачите следят активно и събитията в технологичната, политикорегулаторната и конкурентната сфера. Така например, екологичните тревоги могат да причинят промени в поведението на бизнес купувача и да доведат до отказ от закупуването на определени суровини или консумативи, оказващи вредно влияние върху околната среда. Това от своя страна води до предпочитане на доставчик, демонстриращ социално отговорно поведение и предлагащ екологосъобразни продукти във възможно най-голяма степен. Следователно, „необходимо е да се отбележи, че пазарната ситуация също влияе върху процеса на вземане на решение за покупка“" (Goranova \&Yankov, 2009, p. 116).

Фактори на организацията. Всяка организация има специфични цели, политики, 
процедури, организационни структури и системи за осъществяване на покупките. Специалистите по маркетинг за бизнес организациите трябва да имат ясна представа за следните тенденции при купуването:

- Повишаване равнището на отделите за покупки. Подтикнати от конкурентния натиск, компаниите все повече включват в отделите си по покупки хора с научни степени и с аспирации някой ден да станат главни изпълнителни директори. Тези нови, с по-стратегически позиции отдели по доставките и снабдяването търсят най-добрата стойност от по-малко и по-добри доставчици. В много мултинационални компании отделите по покупки са издигнати в ранг „отдели за стратегическо снабдяване” с отговорност за глобалните източници и партньорство. В отговор на тази тенденция специалистите по маркетинг трябва да повишат равнището на своя търговски персонал, за да е равностоен на бизнес купувачите;

- Интердисциплинарни роли. Проведени изследвания сред големи компании показват, че повечето професионалисти в пазаруването описват своята работа като по-стратегическа, техническа, екипно ориентирана и включваща повече отговорности от преди. През последните години групите по покупките все повече са свързани с проектирането и развоя на нови продукти, като участват във вземането на решения във връзка с цялостния жизнен цикъл на предлаганите от техните компании продукти;

- Централизирано пазаруване (снабдяване). В компаниите с много поделения повечето от покупките се извършват от отделни звена поради различните нужди на поделенията. В наше време обаче, много компании започват да централизират процеса, като определят кои материали, купувани от поделенията, ще се пазаруват централизирано, за да се спечели повече. Отделните поделения могат да купуват от други източници, ако успеят да договорят по-добра цена, но централизираното пазаруване обикновено води до значителни спестявания. За специалиста по бизнес маркетинг това означава, че ще си има работа с по-малко, но на по-високо равнище купувачи и ще трябва да използва търговска група в национален мащаб, за да се справи с големите корпоративни клиенти;

- Децентрализирано пазаруване на евтини артикули. При определени операции по пазаруването все още се запазва тенденцията за децентрализация, във връзка с което отделни служители са упълномощени да купуват някои евтини стоки. Това намалява разходите за обработка на порьчки с малка стойност. В дългосрочен план по този начин купувачите и доставчиците могат да отделят по-малко време за документация, така че търговските отдели да имат повече време за изграждане на партньорски отношения;

- Пазаруване чрез интернет. Преходът към търгуването чрез интернет води до дългосрочни промени. Компаниите не само създават собствени уебстраници, за да продават на бизнес клиенти, но изграждат и интранет мрежи за вътрешни комуникации и екстранет мрежи за връзка с регулярните доставчици и дистрибутори. Снабдяването он-лайн позволява да се намалят разходите по сделките и по персонала, както и времето между поръчка и доставка, като по този начин пазаруването се консолидира. Пазаруването чрез интернет може да помогне за създаване на по-близки отношения между партньорите и купувачите, а освен това изравнява условията за малките и за големите доставчици. Не трябва да се забравя обаче, че то може и да ерозира лоялността между доставчик и клиент, и да отвори вратата за евентуални несполуки в областта на сигурността; 
- Дългосрочни договори. Бизнес купувачите все повече инициират и приемат дългосрочни договори с надеждни доставчици. Много мултинационални компании предпочитат да купуват от по-малко доставчици, вкл. и такива, които са склонни да се преместят по-близо до заводите на компанията и да произвеждат висококачествени части за нея. Освен това специалистите по бизнес маркетинг разработват системи за обмен на електронни данни, за да могат техни клиенти да влязат в тях и да направят поръчките си по електронен път;

- Оценка на дейността на купувачите и професионалното им развитие. Много компании имат стимулиращи системи за възнаграждение на мениджърите по покупките за добрата им работа, също както тьрговският персонал получава премии за сполучливи продажби. Тези системи карат мениджърите по покупките да увеличат натиска върху продавачите, за да постигнат по-добри резултати;

- „Стройно” производство. Много производители преминават към т.нар. стройно производство, което им дава възможността да произвеждат повече и повисококачествени продукти при по-малки разходи и за по-малко време. Стройното производство включва производства „точно навреме” (Justintime - JIT), постриктен контрол върху качеството, постоянно и надеждно снабдяване, доставчици, ситуирани по-близо до клиентите, компютьризирано пазаруване, стабилни производствени графици, с които доставчиците разполагат, един източник на доставка с включване на доставчика на ранен етап. JIT II следващото равнище на партньорство между клиента и доставчика, се фокусира върху намаляване на разходите и ськращаване на времето за всекидневните транзакции, като на място при клиента заработва един (или повече) представител на доставчика, който изпълнява ролята на плановик по доставянето на материалите. Това е ново, нетрадиционно споразумение, основаващо се на изграденото дългогодишно доверие между страните.

Междуличностни фактори. Центровете за покупка обикновено включват няколко участници с различни убеждения, интереси, власт, статус, симпатии и убедителност. Малко вероятно е специалистьт по бизнес маркетинг да знае каква е динамиката в групата по време на процеса на вземане на решение. Ето защо, далновидните фирми се опитват да узнаят колкото е възможно повече за отделните участници в центъра за покупки и за техните взаимоотношения, както и да обучат търговския си персонал и други хора от маркетинговата организация да долавят по-точно влиянието на междуличностните фактори.

Индивидуални фактори. Всеки купувач има лични мотивации, възприятия и предпочитания, които се влияят от възрастта, доходите, образованието, поста, индивидуалността, отношението към риска и културата. Нещо повече, купувачите определено демонстрират различен стил на пазаруване. Така например, някои по-млади, високообразовани купувачи са специалисти по изготвянето на строги компютъризирани анализи на конкурентните предложения преди да изберат доставчика. Други купувачи са от т.нар. стара школа и често предприемат действия, с които да настройват конкурентите един спрямо друг, предизвиквайки пряка конкурентна борба за спечелването на дадена поръчка. „Потребителят е този, който определя качеството като сравнява предлаганите от тьрговеца стоки и услуги със собствените критерии или с предлагани от други търговци аналогични такива. Поставянето на преден план на потребителната стойност поставя въпроса за конкурентоспособността на търговското предприятие“ (Ilieva, 2016, p. 156). Съобразяването с тези фактори ще помогне на специалистите по маркетинг в работата им с отделните хора в центровете по покупки.

Културни фактори. Опитните специалисти по маркетинг внимателно изучават 
културата и навиците на всяка страна или регион, където искат да продават продуктите си, за да разберат културните фактори, които влияят върху купувачите и пазаруващите организации. „Ориентацията към клиента е тип организационна култура и осъзнаването на този факт и целенасоченото налагане на подобен вид организационна култура може да доведе до спестяване на значителни финансови средства и време“" (Stanimirov, 2010, p. 197). Онези, които продават на фирми в други държава, трябва да са наясно с най-важните специфики на културните отношения и практики в отделните страни, тъй като те могат да имат значително влияние върху транзакциите „бизнес-за-бизнес” (B-to-B).

\section{Заключение}

Поведението на бизнес купувача се отнася до поведението при покупка на организациите, купуващи стоки и услуги, използвани от тях в производството на други продукти и услуги, които те продават, дават под наем или доставят на други. Наред с това, то включва поведението на фирми, тьргуващи на дребно и на едро, които купуват стоки, за да ги препродават или дадат под наем на други с печалба. В процеса на покупка бизнес купувачите определят какви стоки и услуги трябва да закупят техните организации,след което намират, оценяват и избират между алтернативните доставчици и марки.

Ето защо, специалистите по т.нар. „бизнес-за-бизнес” (B-to-В) маркетинг трябва да направят всичко възможно, за да разберат бизнес пазарите и поведението на бизнес купувачите. Познаването на основните процеси на бизнес пазаруването и динамиката му, позволява на продавача да предложи оферта, която да дава на целевите бизнес купувачи превъзхождаща стойност. След това, подобно на бизнесите, които продават на крайните потребители, маркетинговите специалисти трябва да изградят рентабилни взаимоотношения с бизнес клиентите, които създават по-висока стойност за потребителите.

\section{References}

1. Ilieva, L. (2016) Kachestvoto - factor za konkurentosposobnost na turgovskoto predpriyatie, Turgovskiya $i$ turisticheskiya biznes $v$ usloviyata na inteligenten, ustoichiv I priobshtavasht rastezh. Svishtov: Tsenov

2. Goranova, P., Yankov, N. (2009) Integralen marketing. Svishtov: Tsenov

3. Kotler, P. (2000) Kotler za marketinga. Sofia: Klasika I stil

4. Perkov, V., Koralev, Y. (2012) Organizatsia i tehnologia na dostavkite. Veliko Turnovo: Faber

5. Stanimirov, E. (2010) Upravlenie na vzaimootnosheniata s klienti. Varna: Nauka i ikonomika

6. Stanimirov, E. (2007) Potrebitelsko povedenie, Povedenie na organizatsiite kupuvachi. Varna: Nauka i ikonomika

7. Webster, F., Wind. Y. (1972) A General Model for Understanding Organizational Buying Behavior. Journal of marketing 